\title{
Immunization and helplessness phenomena in the rat in a nonaversive situation
}

\author{
G. P. MULLINS and A. H. WINEFIELD \\ The University of Adelaide, Adelaide, South Australia 5001
}

\begin{abstract}
The performance of rats on a visual discrimination task was found to be impaired following experience with an insoluble problem. The experiment was designed in order to preclude the possibility that the effect could be attributed to the development of an incompatible response. Prior experience with a soluble problem significantly reduced the deleterious effects of the insoluble problem. The results were interpreted as providing evidence of learned helplessness and behavioral immunization in a context where no aversive stimulation was employed.
\end{abstract}

In recent years, evidence has accumulated which seems to show that the phenomenon of learned helplessness (Seligman \& Maier, 1967) is demonstrable in a variety of species and does not depend on experience with a noxious stimulus. Studies by Bainbridge (1973) and Hiroto and Seligman (1975) have been cited as evidence that experience in an insoluble problem situation may be sufficient to produce impaired performance in both humans and rats following transfer to a different, soluble, problem. Unfortunately, Bainbridge's results are also consistent with a different interpretation. Because his rats developed strong position preferences in response to the insoluble problem and because his transfer tasks involved spatial mazes, it is arguable that the impaired performance that he found was due to the development of an incompatible response rather than to a general lowering of motivation (learned helplessness). It has also been shown that prior experience of control over events may have an "immunizing" effect which offsets the effects of subsequent lack of control (Seligman, Rosellini, \& Kozak, 1975).

In the study reported here, the effects of experience in an insoluble problem situation were studied with and without prior experience in a soluble problem situation. On the basis of the learned helplessness hypothesis, it was predicted that prior experience with a soluble problem would produce less interference with subsequent learning because of the immunizing effect of the pretreatment.

In order to rule out the possibility that the observed effects of the experimental operations might be attributable to the development of an incompatible response rather than to a decreased level of motivation, subjects were trained in a circular discrimination apparatus (Winefield \& Jeeves, 1970). This apparatus enables the experimenter to vary the likelihood that rats will develop position preferences which are incompatible with the consistent choice of the positive stimulus. For example, where
12 doors are available (alternately positive and negative), subjects tend to choose doors in the vicinity of their initial position but they do not restrict their choices to particular doors or particular positions (Winefield \& Mullins, 1976). By contrast, where subjects are only permitted access to two adjacent doors, they tend to develop preferences for the right or left door, which is incompatible with consistent choice of the positive stimulus (inasmuch as the latter is sometimes on the left and sometimes on the right).

On the basis of the findings of Mullins, Winefield, and Levy (1973, Experiment 3), it was anticipated that performance would be independent of the number of doors available to the subjects.

\section{METHOD}

\section{Experimental Design}

A 2 by 2 by 2 factorial design was used. The three factors were: prior experience with a soluble problem vs. no such prior experience (immunization factor); experience vs. no experience with an insoluble problem (insoluble factor); and training with 2 doors vs. training with 12 doors (incompatible response factor).

The experiment was conducted in three phases. In Phase 1, half the subjects were trained to criterion on an easy visual discrimination problem. In Phase 2, half the subjects were placed in an insoluble problem situation in which they were randomly reinforced on $50 \%$ of trials. In Phase 3, all subjects were trained to criterion on a different visual discrimination. Throughout all three phases, half the subjects had access to only 2 adjacent doors and half had access to 12 doors.

The experimental conditions administered to the eight groups are summarized in Table 1 .

\section{Subjects}

The subjects were 72 experimentally naive male Wistar strain rats, approximately 100 days old at the beginning of pretraining. The subjects were on a $24-\mathrm{h}$ feeding schedule and were maintained at $85 \%$ of their ad-lib body weight throughout the experiment. Water was available at all times.

\section{Apparatus}

All subjects were run in a circular apparatus, which has been described in detail elsewhere (Winefield. 1974; Winefield \& Jeeves, 1970). Briefly, each subject was placed on a central starting plat- 
Table 1

Experimental Conditions for the Eight Groups

\begin{tabular}{lccc}
\hline & \multicolumn{1}{c}{ Greatment } \\
\cline { 2 - 4 } Group & Phase 1 & Phase 2 & Phase 3 \\
\hline $\begin{array}{l}\text { Immunization/Insoluble/2 Door } \\
\text { Immunization/Insoluble/12 Door } \\
\text { Immunization/No Insoluble/2 Door }\end{array}$ & B/W & Random Reinforcement & H/V \\
Immunization/No Insoluble/12 Door & B/W & & H/V \\
$\begin{array}{l}\text { No Immunization/Insoluble/2 Door } \\
\text { No Immunization/Insoluble/12 Door } \\
\text { No Immunization/No Insoluble/2 Door } \\
\text { No Immunization/No Insoluble/12 Door }\end{array}$ & & Random Reinforcement & H/V \\
\hline
\end{tabular}

form surrounded by 12 goal compartments, each containing food. The compartments could be entered by the subject's crossing a $7.5-\mathrm{cm}$ air gap onto a $11.5-\mathrm{cm}$-deep shelf and going through a top-hinged door. Each door could be locked by means of a rotating arm, and different discriminanda could be clipped onto the front. The entire apparatus was surrounded by curtains, and lighting was provided by means of an overhead globe $(60 \mathrm{~W})$ situated directly above the starting platform. In this situation, extraneous visual cues, which have been shown to be relied upon by rats for spatial orientation (Restle, 1957), were eliminated. For purposes of comparison with the normal two-choice situation, 10 of the compartments could be screened off by means of a flexible piece of metal which was clipped onto the partitions between the goal compartments.

\section{Procedure}

Because of the number of subjects involved, the experiment was run in two stages, with 40 subjects in the first and 32 subjects in the second stage. All experimental conditions were represented in each stage.

Pretraining. After 7 days of handling, during which subjects were reduced to $85 \%$ of their ad-lib weights, preliminary training was begun. Subjects were randomly allocated to groups and underwent 8 days of training with mid-gray doors in 12- and 2-door situations, respectively. Pretraining was continued until all the rats were responding confidently in the sense that they would leave the starting platform, open the goal compartment doors, and eat in the goalbox. The subjects were given experience with locked doors; position responding in 2-door subjects was discouraged by locking the door on the preferred side.

Phase 1: Initial discrimination (immunization). Half the subjects from both 2 - and 12-door groups (18 from each) were trained to a criterion of $22 / 24$ correct responses over 2 successive days on a black-white discrimination. Black and white plates were clipped onto the 12 doors in an alternating pattern. Nine rats in each group had black as $\mathrm{S}+$ and nine had white as $\mathrm{S}+$. The subjects were run in squads of three or four with an intertrial interval of about $3 \mathrm{~min}$. The within-squad order by which the subjects were run varied systematically from day to day, utilizing the various possible combinations of within-squad order. The order in which groups were run was alternated between the 2 - and 12-door groups from day to day.

The rats were given 12 noncorrection trials per day with $\mathrm{S}$ always locked, although there was food behind both locked and unlocked doors. The 12-door subjects were placed on the starting platform facing a different partition between a pair of doors on every trial. Thus, 12 trials ensured that each of the 12 partitions or 12 adjacent pairs of doors would be encountered once a day. For the 2-door subjects, this procedure involved moving the screen on every trial so as to expose a different pair of doors. The order in which the partitions were faced varied from day to day according to Fellows' (1967) series. There was no limit to the time allowed for the subjects to respond. Correct responses were rewarded by $10 \mathrm{sec}$ access to the container of pellets of dry compressed food, which was in all 12 compartments. In the case of an incorrect response, the rat was removed from the apparatus as soon as it made contact with a locked door and returned to the home cage. On the day following attainment of the learning criterion, nine 12-door subjects and nine 2-door subjects were transferred to the horizontal-vertical discrimination (Phase 3) and the remainder were transferred to an insoluble problem (Phase 2). Subjects were alloted to these conditions on the basis of their attainment of the initial learning criterion.

Phase 2: Insoluble problem. Nine 12-door subjects and nine 2-door subjects from Phase 1 and nine 12-door and nine 2-door naive rats were given 60 trials ( 5 days) of "random" reinforcement. On half of the daily trials, the white doors were locked and the black doors were unlocked, and vice versa. For the 2-door subjects, the door on the right was locked on half the daily trials and the door on the left was unlocked, and vice versa. Both random reinforcement and the position of the unlocked door were determined by Fellows' (1967) series; i.e., the random reinforcement was not truly random but was such that no response pattern could gain reinforcement on more than $50 \%$ of the daily trials. For all groups, the black and white discriminanda were present during random reinforcement.

Phase 3: Transfer training. All subjects were trained to a criterion of $22 / 24$ correct responses over 2 consecutive days on the horizontal-vertical discrimination with the same procedure, as had been used in Phase 1. The discriminanda consisted of black and white stripes, $1.2 \mathrm{~cm}$ wide, which alternated in a horizontal or vertical pattern. As far as possible the subjects were run in groups of three or four with an intertrial interval of 2-3 min. The subjects were allotted to groups with horizontal as $\mathrm{S}+$ or vertical as $\mathrm{S}+$ as equitably as possible in order to balance stimulus preference and individual differences in learning ability. In each group, five subjects had horizontal as $\mathrm{S}+$ and four had vertical as $\mathrm{S}+$.

\section{RESULTS}

Trials to criterion for the various treatments on the transfer task (Phase 3) are illustrated in Figure 1. There was no significant difference between the four groups that learned the initial black-white discrimination $(F<1)$. This was convenient in that these groups could be more easily compared on performance in the transfer task.

Those subjects which were trained on the initial discrimination (Phase 1) and were then transferred to the insoluble problem in Phase 2 continued to respond to the stimulus which had been their $\mathrm{S}+$ during the initial discrimination.

A 2 by 2 by 2 analysis of variance of the trials to 


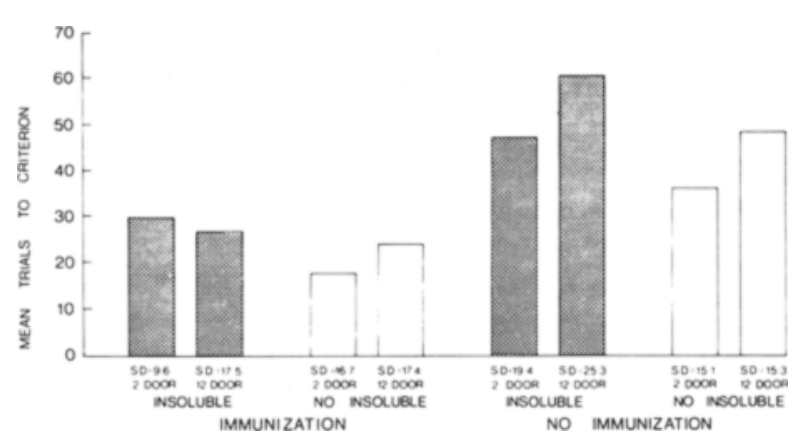

Figure 1. Trials to criterion on the horizontal-vertical transfer task (Phase 3).

criterion on the horizontal-vertical transfer task indicated significant main effects for the immunization factor $[F(1,64)=28.81, p<.001]$ and for the insoluble factor $[\mathrm{F}(1,64)=4.92, \mathrm{p}<.05]$, but not for the incompatible response factor $[F(1,64)=$ $2.68, p>.05$ ]. None of the interaction effects was significant. For the no-immunization condition, individual comparisons revealed significant differences between the insoluble and no-insoluble groups. For the 2-docr groups, $\mathrm{t}(64)=2.56, \mathrm{p}<.01$, and for the 12-door groups, $\mathrm{t}(64)=2.90, \mathrm{p}<.01$.

\section{Position Responding}

The amount of position responding observed in the 2-door groups is summarized in Table 2 in terms of the number of days on which subjects choose one side on more than 9 out of 12 trials. Since half the subjects scored 0 days of position responding in the course of the transfer task, a nonparametric KruskalWallis one-way analysis of variance (Siegal, 1956) was used to analyze the data. The difference between the groups in Phase 3 was significant $(\mathrm{H}=9.61$, $\mathrm{df}=3, \mathrm{p}<.05$ ), and further analysis indicated that the groups that learned the initial black-white discrimination displayed less position responding than those that did not (Mann-Whitney $U=82, p<.05$ ).

As regards the 12-door subjects, it is possible to conceive of position responding being displayed by these subjects, in the sense that when placed facing the partition between two doors the rat could go consistently to the left or right door, presumably on the basis of proprioceptive cues. Certainly, this is not the only form of position responding available to the 12-door subjects, but it does provide a measure of position responding which compares in a meaningful way with that applied to the 2-door subjects. In fact, only 6 days of position responding were recorded throughout the entire experiment for these subjects. Another form of systematic behavior, available only to the 12 -door subjects, is a preference for one particular door. This is a pattern of responding which one would expect if the rats used auditory, olfactory, or tactile cues which were not apparent to the experimenter. The mean number of responses to the most preferred or most frequently chosen door is shown in Table 2 . The expected frequency of response, if the subjects' choices were indeed randomly distributed across all the available doors, is between 2.9 and 3.9 , and the observed frequencies fell within these limits.

\section{DISCUSSION}

The results of this experiment clearly demonstrated that experience with an insoluble problem interfered with the subsequent acquisition of a discriminative response. This interference could not be attributed to the development of an incompatible position response because it was not related to the number of doors which were available to subjects. Subjects trained using a conventional 2-door procedure displayed the normal position responding which characterizes visual discrimination learning and which is incompatible with the consistent choice of the positive stimulus. On the other hand, subjects trained using the 12-door procedure displayed no systematic behavior that was incompatible with the consistent choice of the positive stimulus.

Prior experience with the soluble problem produced a very strong positive effect which almost completely obliterated the deleterious consequences of the subsequently presented insoluble problem. This apparent immunization effect provides an interesting parallel to that recently demonstrated by Seligman, Rosellini, and Kozak (1975) against be-

Table 2

Position Responding by 2-Door Subjects and Door Preferences of 12-Door Subjects

\begin{tabular}{|c|c|c|c|c|c|c|}
\hline \multirow[b]{2}{*}{ Group } & \multicolumn{3}{|c|}{$\begin{array}{c}\text { Position Responding by } \\
\text { 2-Door Subjects* }\end{array}$} & \multicolumn{3}{|c|}{$\begin{array}{l}\text { Door Preferences of } \\
\text { 12-Door Subjects** }\end{array}$} \\
\hline & Phase 1 & Phase 2 & Phase 3 & Phase 1 & Phase 2 & Phase 3 \\
\hline Immunization/Insoluble & 1.7 & 0 & .7 & 3.0 & 3.2 & 2.9 \\
\hline Immunization/No Insoluble & 2.8 & & .4 & 3.0 & & 3.4 \\
\hline No Immunization/Insoluble & & 2.1 & 2.4 & & 3.0 & 3.2 \\
\hline No Immunization/No Insoluble & & & 1.1 & & & 3.0 \\
\hline
\end{tabular}

*Mean number of days of more than 9/12 to one side.

**Mean number of trials per day on which most preferred door was chosen. 
havioral disruption caused by electric shock.

In two respects, the results provide powerful support for the theory of learned helplessness as recently expounded by Seligman $(1975$, p. 56): "The expectation that an outcome is independent of responding (1) reduces the motivation to control the outcome; (2) interferes with learning that responding controls the outcome." Not only did experience with an insoluble problem retard subsequent learning, as Bainbridge (1973) found, but also the fact that no differences occurred between subjects presented with 12 doors as opposed to 2 doors ruled out the possibility that the interference was caused by an incompatible position response-an interpretation that would be consistent with Bainbridge's results. The reduced interference produced by prior experience with a soluble problem provided important evidence of the generality of behavioral immunization previously demonstrated in both dogs (Seligman \& Maier, 1967) and rats (Seligman, Rosellini, \& Kozak, 1975) following experience with inescapable shock.

Although we have chosen to interpret our results in terms of learned helplessness, they are also consistent with the related hypothesis of "learned irrelevance"' (Baker, 1976; Mackintosh, 1973). It could be argued that, under the insoluble condition, rats learned that the visual stimuli presented to them were uncorrelated with reinforcement. The immunization effect would be due to interference with such learning caused by prior contrary experience. This interpretation has the advantage that it does not assume response-independent reinforcement, which is a normal prerequisite for the demonstration of learned helplessness (Maier, Seligman, \& Solomon, 1969).

Other evidence of a non-aversive parallel to learned helplessness has been reported using pigeons. Engberg et al. (1972) have shown that autoshaping (pecking a lighted key which signals food presentation) is retarded following prior experience of unsignaled food presentations. They explained this retardation in terms of "learned laziness," an appetitive extension of learned helplessness. Although further evidence supporting such a notion has recently been reported by Welker (1976), the learned laziness interpretation has been challenged in a recent paper by Tomie (1976). Tomie proposes an alternative explanation in terms of blocking (Kamin, 1969), a retardation of conditioning caused when a CS is compounded with another stimulus which has previously been paired with the US. This explanation assumes that the background, contextual stimuli serve to block the acquisition of autoshaping.

It is conceivable that such a context-blocking effect may have occurred in the present experiment and could explain the retarded learning found in the insoluble subjects. Additional experimentation which systematically varies the contextual stimuli is needed to test this explanation.

\section{REFERENCES}

Bainbrudge, P. L. Learning in the rat: Effect of early experience with an insoluble problem. Journal of Comparative and Physiological Psychology, 1973, 82, 301-307.

BAKER. A. G. Learned irrelevance and learned helplessness: Rats learn that stimuli, reinforcers, and responses are uncorrelated. Journal of Experimental Psychology: Animal Behavior Processes, 1976, 2, 130-141.

Engberg, L. A., Hansen, G., Welker, R. L., \& Thomas, D. R. Acquisition of key-pecking via autoshaping as a function of prior experience: "Learned laziness"? Science, 1972, 178, $1002-1004$.

Fellows, B. J. Chance stimulus sequences for discrimination tasks. Psychological Bulletin, 1967, 67, 87-92.

Hiroto, D. S., \& Seligman, M. E. P. Generality of learned helplessness in man. Journal of Personality and Social Psychology, 1975, 31, 311-327.

Kamin, L. J. Predictability, surprise, attention and conditioning. In B. A. Campbell \& R. M. Church (Eds.), Punishment and aversive behavior. New York: Appleton-Century-Crofts, 1969.

Mackintosh, N. J. Stimulus selection: Learning to ignore stimuli that predict no change in reinforcement. In R. A. Hinde \& J. Stevenson-Hinde (Eds.), Constraints on learning. New York: Academic Press, 1973.

Maier, S. F., Seligman, M. E. P., \& Solomon, R. L. Pavlovian fear conditioning and learned helplessness. In B. A. Campbell \& R. M. Church (Eds.), Punishment and aversive behavior. New York: Appleton-Century-Crofts, 1969.

Mullins, G. P., Winefield, A. H., \& Levy, C. The effect of frustration and reduced spatial cues on visual discrimination and reversal learning in rats. Australian Journal of Psychology, $1973,25,233-241$.

Restle, F. Discrimination of cues in mazes: A resolution of the 'place versus response' question. Psychological Review, 1957, 64, 217-228.

Seligman, M. E. P., \& Maier, S. F. Failure to escape traumatic shock. Journal of Experimental Psychology, 1967, 74, 1-9.

Seligman, M. E. P., Rosellin, R. A., \& Kozak, M. J. Learned helplessness in the rat: Time course, immunization, and reversibility. Joumal of Comparative and Physiological Psychology, 1975, 88, 542-547.

SIEGEL, S. Nonparametric statistics for the behavioral sciences. New York: McGraw-Hill, 1956.

TomiE, A. Interference with autoshaping by prior context conditioning. Journal of Experimental Psychology: Animal Behavior Processes, 1976, 2, 323-334.

WELKER, R. L. Acquisition of a free-operant-appetitive response in pigeons as a function of prior experience with responseindependent food. Learning and Motivation, 1976, 7, 394-405.

WinEFIELD, A. H. The effect of reduced spatial cues on the learning of successive visual reversals. Quarterly Journal of Experimental Psychology, 1974, 26, 196-205.

Winefield, A. H., \& JeEves, M. A. The circular maze: An apparatus for studying simultaneous discrimination learning in the rat. Australian Journal of Psychology, 1970, 22, 71-74.

Winefield, A. H., \& Mullins, G. P. Matching and maximizing behaviour in the rat. Australian Journal of Psychology, 1976, 28, 73-81.

(Received for publication October 12, 1976; revision accepted April 18, 1977.) 